\title{
The Mind of the Reader: Mind Genomics Cartographies of E-Readers versus 'New' Magazines
}

\author{
Howard Moskowitz ${ }^{1 *}$, Konstantin Savicevic ${ }^{2}$, Martin Braun ${ }^{3}$ and Laura Estefania Rodriguez ${ }^{4}$ \\ ${ }^{1}$ WICE, World Institute of Competitive Excellence, New York USA, and Mind Genomics Associates, New York, USA \\ ${ }^{2}$ TINO SPACE, Belgrade, Serbia \\ ${ }^{3}$ Queens College of the City University of New York, New York, USA \\ ${ }^{4}$ University of Ariandina, Bogota, Colombia
}

*Corresponding author: Howard Moskowitz, WICE, World Institute of Competitive Excellence, New York USA, and Mind Genomics Associates, New York, USA

Received: January 19, 2022; Accepted: January 26, 2022; Published: January 31, 2022

\begin{abstract}
In two separate experiments, groups of 50 respondents evaluated vignettes comprising systematically varied combinations of elements, experiment 1 dealing with the content of magazines, experiment 2 dealing with the features of an e-book reader. The vignettes were evaluated on 9-point Likert scales. Equations relating the presence or absence of the 36 elements in each experiment revealed unusually high coefficients. Clustering the patterns of coefficients revealed two mind-sets for the magazine contents, three mind-sets for the e-book reader. The mind-sets were not diametrically opposite, in the way the clustering would show for most products. Rather, the mind-sets suggested different patterns of preference, instead of preference/rejection. The argument is made that for many products with positive features, mind-set segmentation will reveal groups differing in the order of preference, with most features liked, rather than revealing the more typical finding that the mind-sets exhibit strong and opposite patterns of acceptance/rejection.
\end{abstract}

\section{Introduction}

The $21^{\text {st }}$ century abounds in media, formerly just printed and broadcast, now electronic. Over the past decades readers have been introduced to the benefits of e-readers, virtually small computers created for the presentation of written material of many sorts, from books presented as searchable files, to pictures, presentations, to audio books, and the like. At the same time, the $21^{\text {st }}$ century abounds in the printed word, on traditional media, such as newspapers, magazines, books, and so forth.

The focus of the two studies reported here was on the response to magazines (study \#1), and to e-book readers (study \#2), from the point of view of first- and second-year college students entering the world of higher education. The idea was to find out what features they thought would be relevant to people, and in turn, how people felt about combinations of these features in small vignettes (descriptions of offerings) and evaluated by respondents.

The academic literature as well as the business literature focuses on who reads magazines [1] and who uses e-book readers and the reasons [2-6]. The studies on media give one a sense of looking from the outside in, from the point of view of a third-party observer trying to make sense of a situation and reporting on the various features of situation. The observer is describing what she or he sees, and the potential organizing patterns which might be emerging, based what is observed, and the intuition of the observer. There is a sense of the 'inside of the mind', but not a feeling of immediacy, the type of immediacy when one reads a description of a product or service, and feels an excitement, a sense of 'that's just what I want.'

\section{Rationales for the Two Studies Reported Here}

The original studies were conducted as part of a set of studies at Queens College, (CUNY, NY), by students turned experimenters. The focus was on exploring the world of the everyday. One remarkable event emerged from the two studies. The study magazines were perceived by many of the respondents as fairly boring. Many of the elements were simply uninteresting, and in fact 22 of the respondents did not end up liking anything in that was being offered. In contrast, all the elements in the e book reader were considered interesting. Thus, it was of interest to compare the two.

The Mind Genomics process makes what was a typical questionnaire into an experiment. The questionnaire and the experiment both try to uncover what respondents feel to be important. The questionnaire works by presenting the respondent with a single set of stimuli, messages or elements presenting different ideas, and analyzing the ratings. The stimuli may be of the same type, presenting alternatives of a single idea, or the stimuli may be of entirely different categories of messages. In contrast, Mind Genomics can be said to an experiment in which the respondent rates combinations of messages, simulating a typical reality [7-9].

The approach is illustrated by a series of steps, each step comparing the two studies.

\section{Step 1: Select the Topic, the Questions, and the Answers} (elements)

Mind Genomics works with the experience of the everyday. It is critical, therefore, to select a delimited topic, and create a story framed 
by questions, in the manner that a story might be related by a person. The questions provide the structure to move the story forward. The story need not be the type of story with a plot. Rather, the story merely needs to provide a set of smaller 'sub-topics', aspects of the main topic, but aspects that can be dealt with by simple stand-alone phrases which 'describe.' The topic will be introduced to the respondent, so the respondent knows to what the test stimuli pertain. Th questions are never shown to the respondent, but simply serve as an aid to creating the answers, the elements, which will be shown to the respondent in test combinations.

Table 1A shows the structure of topic, questions, and answers for the magazine, something with which people were very familiar at the time of the study, in 2012. The topic was particularized to a subscription to the magazine, rather than interest in general in the magazine. The elements would be looked at in the light of a call to action, to subscribe or not to subscribe to the magazine.

Table $1 \mathrm{~B}$ shows the structure of topic, questions, and answers for the E-reader. At the time of the study, E-readers were coming into vogue. Amazon had introduced the Amazon Kindle series, E-book readers, so the product idea was becoming better known. Technology was evolving quickly. The focus of the study was features and capabilities of the product.

Allowing people to collaborate, especially students who are as yet unfettered by the cynicism of adults, generates ideas which run the gamut. The elements shown in Tables $1 \mathrm{~A}$ and $1 \mathrm{~B}$ emerged from students, not from professional copyrighters, not from professional 'creatives' whose job it is to come up with winning ideas. The Mind Genomics system encourages the exploration of new ideas, often ideas in the mind of young people. It will be interesting to measure how well these ideas perform. they are certainly different from many of the tried-and-true ideas proffered as the output of professionally moderated creative session. The performance will be measured empirically below

\section{Step 2: Combine the Elements into Short, Easy to Read Vignettes, Using Experimental Design}

Mind Traditional efforts to teach the 'scientific method' are founded on the belief that a variable must be isolated, and studied, but only after all of the possible variation, the 'noise' around the variable has been eliminated, either by suppressing the noise (testing the element by itself $i$ the simplest form), and/or by averaging out the noise (e.g., testing with dozens or even hundreds of people, so that the individual variation averages out).

Mind Genomics was founded on the basic tenet judgment data of real-world stimuli should be done in a way which best resembles the real world, namely mixtures.,,, namely identify the variables to be tested, combine them in a way which resembles th type of compound stimulus which one encounters in nature. By combining the different elements in structured way, using an experimental design, which mixes and matches the different independent variable, one presents the respondents with more realistic test stimuli. We encounter mixtures all the time and react to them. Thus, the mixtures tested by the respondents are more similar to what the person would face. The key difference is that the experimental design permits the research to deconstruct the reaction to this 'combination' into the contributions of the components, the variables of interest.

The requirements for a Mind Genomics experimental design are that the elements should appear equally often, that the vignettes be 'incomplete' (viz., some vignettes are absent elements or answers from a question), that the elements be statistically independent of each other, and the experimental design be valid down to a base size of one respondent. Finally, the experimental design be permutable, so that by permuting elements or answers in a single question new combinations emerge, based upon the same design structure [10].

It is important to note that with the foregoing approach, each respondent evaluates a different set of 48 vignettes, prescribed by the underlying experimental design (called the $6 \times 6$ design; six questions, six answers or elements per question). With 50 or so respondents, there are $50 \times 48$ or 2400 vignettes evaluated by the respondents, most of which are different from each other. In that way the Mind Genomics system is metaphorically like the MRI machine, which takes pictures of the same tissue from different angles and combines these pictures by computer to arrive at a single 3-dimensional image of the underlying tissue.

The output of the experimental design appears in Figure 1A, showing a vignette for the magazine, and Figure $1 \mathrm{~B}$ showing a vignette for the e-book reader.

\section{Step 3: Execute the Mind Genomics Study on the Internet}

Beginning in the late 1990's, a great deal of consumer research migrated to the web, to the internet. Companies found that the data generated by web-based interviews seemed to be just as valid as data generated by in-person interviews and mailed-out paper questionnaires. Establishing web-interviews as a valid way, and indeed far less expensive way, to obtain data gave a boost to interviews which need technology embedded in their backbone. Min Genomics is one of the approaches which proposed, because each respondent was to evaluate a unique set of elements. The only practical way was to have a computer combine the elements in 'real time', following the underlying 3expeirmental design. The process became streamlined over time. The respondent would log in, following a link, be presented with an orientation screen, and then a set of systematically varied combinations, created 'in real time', at the site of the respondent's computer.

Figure $2 \mathrm{~A}$ shows the orientation screen for the magazine study, Figure $2 \mathrm{~B}$ shows the orientation screen for the e-reader study. The respondents were recruited by an online panel provider, Turk Prime, Inc. which provided respondents in the United States. The compensation to the respondents was set by Turk Prime, Inc. as part of their internal policies. These policies as well as the identification of the respondents, were not available through the service. The only guarantee was that the respondents were vetted by Open Venue Ltd., part of their panel.

Figures $2 \mathrm{~A}$ and $2 \mathrm{~B}$ show the orientation screen. Very little information is given regarding the purpose of the study, and the rationale for selecting the elements. Just the topic is given. The rest 
Table 1A: Questions and answers (elements) for the magazine.

\begin{tabular}{|c|c|}
\hline & Question (Category) A: \\
\hline Al & What makes a man a gentleman ... Teaches you to "Look Sharp. Live Smart." \\
\hline A2 & Rockers read it. Pop Stars read it. \\
\hline A3 & Executives read it .. Uneducated ones look at the pictures \\
\hline A4 & The Weekly Newsmagazine \\
\hline A5 & Write the word, submit the word, love the word. \\
\hline \multirow[t]{2}{*}{ A6 } & Tons of Useful Stuff \\
\hline & Question (Category) B: \\
\hline B1 & Seasonal offers style guides inspired by current trends in entertainment \\
\hline B2 & Special issues featuring articles on famous television and music stars \\
\hline B3 & Expanded CD review sections of the months new releases \\
\hline B4 & Hidden city; best summer concerts, events, and specials \\
\hline B5 & Exercise guides to get in shape for your special someone \\
\hline \multirow[t]{2}{*}{ B6 } & In depth discussion of modern-day studies, research, and discoveries \\
\hline & Question (Category) C: \\
\hline $\mathrm{C} 1$ & Free soundtracks or movies per issue with subscription \\
\hline $\mathrm{C} 2$ & Collectible artist of the year covers \\
\hline C3 & Sale Coupons to this season's hottest events and concerts \\
\hline $\mathrm{C} 4$ & Sneak Previews of the upcoming year in music and entertainment \\
\hline C5 & Free Posters in every issue featuring the hottest celebrities \\
\hline \multirow[t]{2}{*}{ C6 } & Contests promoting traveling opportunities to exotic locations \\
\hline & Question (Category) D: \\
\hline D1 & Traditional paper bound Issues \\
\hline D2 & Magazine printed on $100 \%$ Recycled paper \\
\hline D3 & Online viewable and mobile application so the reader can access the magazine at any time \\
\hline $\mathrm{D} 4$ & Emailed newsletters sent to the reader \\
\hline D5 & Social network pages with up to the hour updates that can be discussed with friends \\
\hline \multirow[t]{2}{*}{ D6 } & Daily Podcasts and Video Blogs via Internet and Email \\
\hline & Question (Category) E: \\
\hline E1 & Regularly mailed printed-Issues to your door \\
\hline E2 & Free daily emailed newsletters \\
\hline E3 & Bundles of different magazines according to your preference of taste \\
\hline E4 & Issues sold independently at any newsstand or bookstore at around $\$ 3$ \\
\hline E5 & One time paid mobile apps with downloadable issues and articles on a weekly or monthly basis \\
\hline \multirow[t]{2}{*}{ E6 } & PDF formatted issues emailed to the subscriber \\
\hline & Question (Category) F: \\
\hline F1 & Section for reader's comments and questions \\
\hline $\mathrm{F} 2$ & Survey and poll taking opportunities with prizes \\
\hline F3 & Advice column for the everyday reader \\
\hline F4 & Reader customizable sections for special events or personal projects \\
\hline F5 & Internship opportunities for entrepreneur writers, photographers, graphic designers and future magazine editors \\
\hline F6 & Job opportunities for the future reporters, photographers, and magazine editors \\
\hline
\end{tabular}


Howard Moskowitz (2022) The Mind of the Reader: Mind Genomics Cartographies of E-Readers versus 'New' Magazines

Table 1B: Questions and answers (elements) for the E-Book Reader.

\begin{tabular}{|c|c|}
\hline & Question (Category) A: Environmental Benefits \\
\hline A1 & Ability to write notes within the tablet therefore lowering the need/production of highlighters/pens \\
\hline A2 & Fewer trees cut for paper equals more fresh breathable air \\
\hline A3 & Start breathing in a fresh air \\
\hline A4 & Save trees....save the woods, forest \\
\hline A5 & Solar panel technology allows you to recharge through clean recyclable energy \\
\hline \multirow[t]{2}{*}{ A6 } & Fewer trees cut down means animals won't lose their habitat \\
\hline & Question (Category) B: Screen manufacture \\
\hline B1 & Touchable color screen that's precise \\
\hline B2 & Carry thousands of books on one device \\
\hline B3 & Choose small or large LCD screen \\
\hline B4 & Made of durable material "shock resistant" \\
\hline B5 & Instead of carrying heavy books... try carrying e-books \\
\hline \multirow[t]{2}{*}{ B6 } & Choose your color... Black or Grey \\
\hline & Question (Category) C: Entertainment \\
\hline $\mathrm{C} 1$ & You can now view over 300 million books on one tablet \\
\hline $\mathrm{C} 2$ & Read your favorite magazines, catalogs, and newspapers \\
\hline $\mathrm{C} 3$ & Rent or buy popular movie and TV shows \\
\hline $\mathrm{C} 4$ & Play your favorite games on E-Book \\
\hline C5 & Audio reader is now available to you through E-Book \\
\hline \multirow[t]{2}{*}{$\mathrm{C} 6$} & More apps for your business and studying \\
\hline & Question (Category) D: Quality \\
\hline D1 & Access to the latest technology \\
\hline D2 & Highest quality of E-Book available today \\
\hline D3 & Competitively priced to meet your needs \\
\hline D4 & Long lengthy battery life \\
\hline D5 & Use your friendly menu system \\
\hline \multirow[t]{2}{*}{ D6 } & Tablet made of durable material \\
\hline & Question (Category) E: Education \\
\hline E1 & Promotes reading with the ability to put several book titles within your tablet \\
\hline E2 & Expend your horizon with more knowledge \\
\hline E3 & Life and your future can change... read \\
\hline E4 & Free trial for three weeks \\
\hline E5 & Wi-Fi enable to download books real time \\
\hline \multirow[t]{2}{*}{ E6 } & Become more "tech savvy" with the process of downloading \\
\hline & Question (Category) F: Accessibility \\
\hline F1 & Software download is now easy and fast \\
\hline F2 & Hands on easy to use... no more carrying books \\
\hline F3 & Security systems allow you and only you to access your software \\
\hline $\mathrm{F} 4$ & Latest screen technology makes your book crystal clear to read \\
\hline F5 & Access world of books with a single touch \\
\hline F6 & Color screen for real life reading experience \\
\hline
\end{tabular}




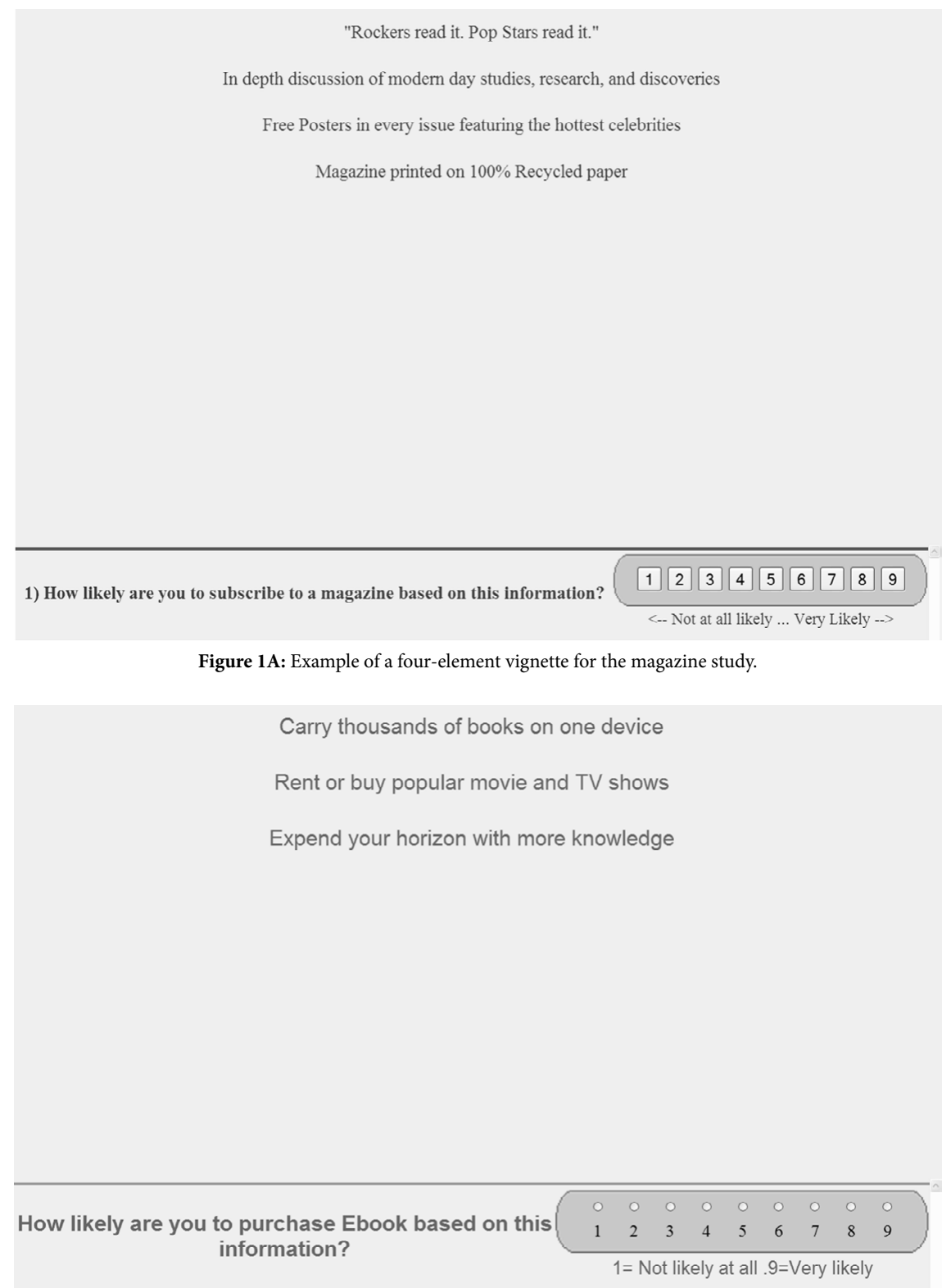

Figure 1B: Example of a 3-element vignette for the e-book reader.

Today, you will be taking a survey regarding Magazine Subscriptions.

You will be seeing different screens of situations regarding Magazine Subscriptions.

Although they may seem similar, each screen combination is unique.

You will be asked two questions for each screen description of combinations:

1) How likely are you to subscribe to a magazine based on this information? 1 = Not Likely ... 9 = Very Likely

2) Based on this screen ALONE... How do you feel when you read these messages?

1 = Excited 2 = Eager 3 = Curious 4 = Uncertain $5=$ Not Interested at All

You will be asked the SAME 2 questions for each screen. Please rate each screen combination as a single unit.

It will take you $10-15$ minutes to complete the study

You can track your progress on the top right of each screen.

Thank you for your participation in this important survey.

Please Click $\gg>$ to Continue.

$\gg$

Figure 2A: Orientation for the magazine study. 


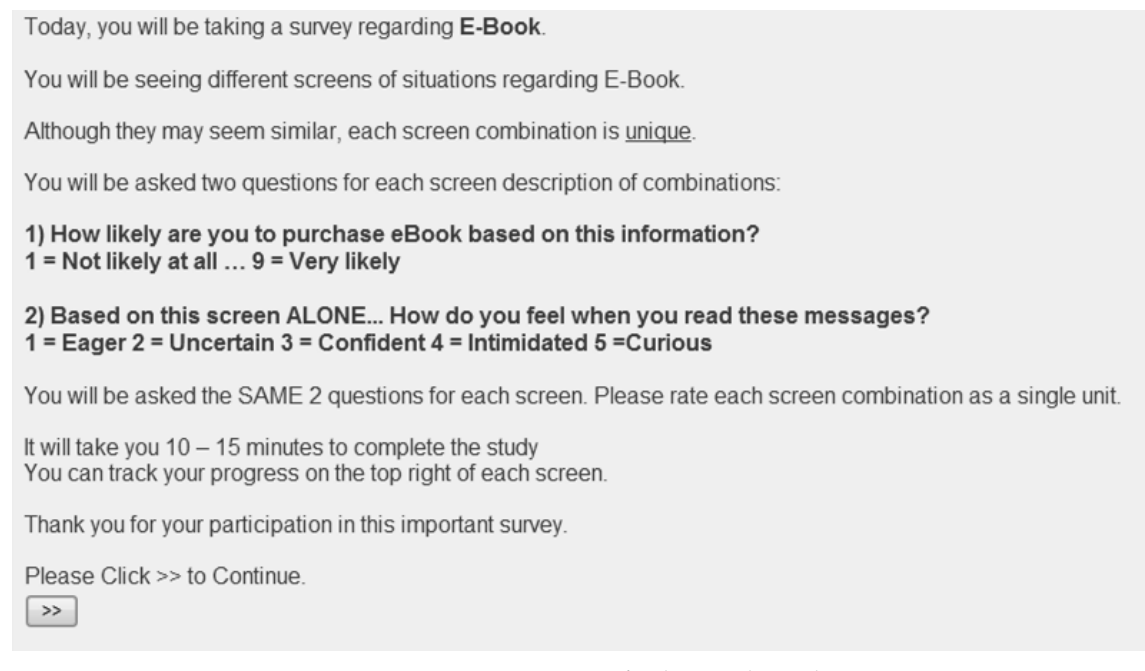

Figure 2B: Orientation screen for the e-reader study.

of the screen provides information about the number of question (two), and the type (scalar, Likert Scale for Question 1, presented here; selection of emotion for each vignette, not presented here).

The orientation screen goes out of its way to reassure the respondent that all the screens are different from each other, and that the study will take 10-15 minutes. These two reassurances were put in after the early experience on the Internet, when respondents kept saying upon exist that the concepts they evaluated seemed to have many repeats (not possible with the design), and that they wanted to know how long the interview would be. Rather than giving a precise time, it was deemed better to give them a reasonable range of 10-15 minutes. Most respondents finished earlier.

Observations of respondents doing these types of studies in a central location revealed that the respondents often begin by trying to 'outsmart' the research, trying to figure out the appropriate answer. With single elements rated, this outsmarting or gaming the system is possible. With 48 different combinations, however, it is impossible for the respondent to game the system. The respondent may begin with an effort to outsmart the system, but almost universally the respondent relaxes, and simply answers in what the respondent feels is an uninterest way, barely paying attention. That tis precisely the right state for the respondent, because in that state the answers come from the heart, without being edited to be politically correct.

\section{Step 4 - Acquire the Data and Prepare It for Analysis}

Each respondent evaluated 48 difeferent vignettes, consturcted according to an experimental deesign. The respondent first rated the vignette in terms of interest using a 9-point category or Likert Scale (subscribe fo the magazine, purchase for the e-book reader). The respondent then ratedthe vignette in terms of emotion experience after reading the vignette. Those data are not presented here.

The foundations of Mind Genomics lie in the fields of experimental psychology, consumer research, and statisitics, respectively. Experimental psychologists do not usually convert the data from the Likert Scales, preferring the granularity, which allows statistical analysis to uncover more statically significant effects using tests of difference. In contrast,, users of Mind Genomics data, typically managers want to use the data for decision making (e.g., use/not use; go/don't go). It is important for them to interpret the data to make their decision. All too often, the manager presented with averages across people from a projecting using Likert Scalesw will begin the interaction by asking a question like 'what does a 6.9 average on the rating scale 'mean', and what should i do?'

The tradition in consumer research and in Mind Genomics, followed here, transforms the Likert sale to a two point scale, 0 and 1 or 0 and 100, repectively. They two transformed scales, $0-1,0-100$, are different expessions of the same data, but present the data either with decimals (0-1), or without decimals (0-100), We chose the $0 / 100$ tranfomration, Ratings of 1-6 were coded 0, ratings of 7-9 were coded 100 , and a vanishingly small random number $\left(<10^{-5}\right)$ was added to make sure the transformed rating would always have variation acfrosss the 48 vignettes for a single respondent. This prophylatic measure ensure that one could use regression modeling at the level of the individual respondent, even in those cases when the respondent confined the ratings to one region, viz., 1-6 or 7-9 respectively.

\section{Step 5 - Create Individual Level Models, through Regression, Relating the Presence/Absence of the Elements to the Transformed Response}

It is at Step 5 that the real analysis begins, an analysis which is virtually mechanical in nature, yet which repeatedly shows how the consumer mind makes decisions. The data were prepared in at Step 4. Step 5 uses OLS (ordinary least squares) multiple regression to relate the presence/absence of the 36 elements to the transformed rating. The equation is expressed as:

Binary Transformed Rating $=\mathrm{k}_{0}+\mathrm{k}_{1}(\mathrm{~A} 1)+\mathrm{k}_{2}(\mathrm{~A} 2) \ldots \mathrm{k}_{36}(\mathrm{~F} 6)$

For those respondents whose ratings were all between 1 and 6 , the coefficients were all near 0 an the additive constant was around 0 as well. For those respondents whose rating whose ratings were all between 7 and 9 , the coefficients again were all near 0 , and the addiive consatn was around 100 . Out of 52 respondents, 22 respondent showed this pattern for magazine, none showed this pattern for 
e-book reader. The data from these 22 respondents were eliminated from the database, leaving only respondents who showed variation in their transformed binary response.

\section{Step 6 - Cluster the Respondents into Either Two Groups (Magazine) or Three Groups (e-Book Reader)}

Step 6 attempts to divide the respondents in a study into clusters, doing so that the the respondents in a clusters are 'similar' to each other, while at the same time the pattern of the 36 averages of the coefficients are very different between two clusters or very different across three clsuters. The process can be done very easily using k-means clustering [11]. The clustering program returns with the assignment of each respondent to exactly one of the two clusters (for magazines), or one of the three clusters (for e-book readers). Afterwards, run one equation for all the respondents in a study, and two separate equations for all respondents in each of the two mind-sets (magazine), three separate eqations for all respondents in each of the three mind-sets (e-book reader).

The clustering procedures are mathematics-based, attempting to bring some definable order into what might otherwise be a blooming, buzzing confusion, in the words of noted Harvard psychologist, William James. The clusters themselves do not have any concrete reality, but simply represent intuitively reasonable ways to divide objects. Clustering can be done on anything, as long as the measure(s) are comparable across the different objects.

When we look at the clusters, recognizing that we are dealing with a mathematically based system, our judgment should be based on at least two criteria. The first criterion is parsimony. We know that we will get perfect clustering if each of our respondents becomes her or his own cluster. That would defeat the purpose. The idea is to create as few clusters as possible, to be as parsimonius as possible, even at the cost of some 'noise' in the system which makes the clustering far less than perfect. Thus, the first rule is the fewer the number of clusters, the better. The second criterion is interpretability, that the clusters should each tell a story. One may want the story to be tight, meaning more clusters, and less parsimony. Or one may allow the story to be less tight, with more open issues, but with more parsimony, viz., fewer clusters. It is always a trade-off; more parsimony versus more interpretability. There is no right answer. In this study, the effort will be towards parsimony, given the range of possible elements that can fit either in a magazine or an e-book reader [12].

One last issues remains to be mentioned. That issue the nature of the variables (elements) considered in the clustering. The traditional approach in Mind Genomics has been to use the coefficients of all of the elements, but not to use the additive constant. There is always the potential that the clustering might be unduly affected by the nature of the elements selected. With 36 elements, one would hope that the elements deal with different aspects in equal ways. But what happens, for example, if most of the elements deal with usage, and only a few elements deal with product features? Would that generate the same clusters were the elements to be configured differently, with only a few elements dealing with usage, and most elements dealing with product features? In other words, is the mind-set segmentation affected by the distribution of the topics dealt with in the study?
To answer the foregoing question, the nature of the variables used in clustering, each study was analyzed twice, AFTER the respondents with all coefficients around the value 0 were eliminated from the data. The first clustering was done with the original 36 coefficients. Both studies comprised featured six sets of six elements each, so the clustering was similar.

The second analysis reduced the dimensionality of the 36 elements using principal components factor analysis [13]. Even though the 36 elements were statistically independent of each other by design, the pattern of 36 cofficients shows substantial co-variations, simply because the elements were similar, generated similar patterns. The PCA isolated eight factors for the magazine subscription, and 15 factors for the e-book reader. The nature of the factors is not important. Rather, the factors are statistically independent of each other. The factors were rotated by Quartimax to make the data matrix as simple as possible. Each respondent was then located in the 8-dimensional factor space for the magazine, or the 15-dimensional factor space for the e-book reader. After the factor spaces were creatd, the clustering was done again, with two mind-sets extracted for the magazine

\section{Step 7: Interpreting the Results - Magazine}

Table $2 \mathrm{~A}$ shows the results for the magazine based upon the clustering into two groups. Three groups did not produce any clearer result. The "Total Panel" data shows all coeficients, positive and negative. For these results, we show only the very strong positive coefficients, 15 or higher.

The three groups, Total, Mind-Set 1 and Mind-Set 2 generate similar, low values for the additive constant, 16-20. The additive constant is the conditional probability of a person wanting to subscribe to the magazine in the absence of elements. The underlying experimental design ensured that each vignette would comprise 3-4 elements, never zero elements. The additive constant is a convenient parameter, estimating the intercept, the likely score in terms of 'top 3 ' that would be obtained in the impossible case of a vignette with no elements.

Table 2B shows the same type of analysis, this time based on the factors of the respondents on eight independent factors (dimensions), rather than on 36 elements.Comparing the two types of segmentation, first based on all 36 elements and the second based on the elements after factor analysis, it is clear the the clustering generates clearer results when the original data is used, confirming the insights of others focused on thepractical uses, opportunities, and pitfalls encountred in clustering $[14,15]$. In reality, Table $2 \mathrm{~A}$, based on all 36 elements, suggests one major mind-set, those interested in experiences. The other mind-set barely enters the picture, only with one element, which scores near the bottom cutoff. Table $2 \mathrm{~B}$ shows the same pattern as well [16].

The final notworthy finding in this study of magazine content is the unusually large number of very strong elements, nine of thirty-six, one quarter, having coefficients of +15 or higher. This is an unusual finding, and may well be attributed to the creative abilities of younger people, ages 17-23, focusing on what is important to them. What is important is the specific, the concrete, the focused feature, not the 
Table 2A: Coefficients for the magazine, for total and two mind-sets, based on using all 36 elements for clustering.

\begin{tabular}{|c|c|c|c|c|}
\hline & $\begin{array}{l}\text { Magazine, Total and Two Mindsets } \\
\text { Clustering based on all } 36 \text { elements }\end{array}$ & $\stackrel{\overrightarrow{0}}{\ddot{E}}$ & 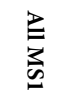 & $\begin{array}{l}\text { 芯 } \\
\text { 离 }\end{array}$ \\
\hline & Base size & 30 & 14 & 16 \\
\hline & Additive constant & 18 & 20 & 16 \\
\hline & Magazine-Mind-Set1 (Based on 36 coefficients) & & & \\
\hline & Magazine: Mind Set 1 - Experiences & & & \\
\hline $\mathrm{C} 3$ & Sale Coupons to this season's hottest events and concerts & 6 & 39 & \\
\hline B5 & Exercise guides to get in shape for your special someone & 16 & 38 & \\
\hline C6 & Contests promoting traveling opportunities to exotic locations & 14 & 37 & \\
\hline $\mathrm{C} 1$ & Free soundtracks or movies per issue with subscription & 12 & 33 & \\
\hline B4 & Hidden city; best summer concerts, events, and specials & 14 & 21 & \\
\hline B3 & Expanded CD review sections of the months new releases & 2 & 17 & \\
\hline $\mathrm{C} 2$ & Collectible artist of the year covers & 0 & 16 & \\
\hline B6 & In depth discussion of modern-day studies, research, and discoveries & 11 & 16 & \\
\hline \multirow[t]{2}{*}{ F1 } & Section for reader's comments and questions & 7 & 15 & \\
\hline & Magazine - Mind-Set 2 - Specific topic geared for men & & & \\
\hline \multirow[t]{2}{*}{ A1 } & What makes a man a gentleman ... Teaches you to "Look Sharp. Live Smart." & -2 & & 16 \\
\hline & Magazine - No strong appeal to either mind-set & & & \\
\hline D2 & Magazine printed on $100 \%$ Recycled paper & 8 & & \\
\hline D4 & Emailed newsletters sent to the reader & 6 & & \\
\hline D6 & Daily Podcasts and Video Blogs via Internet and Email & 5 & & \\
\hline D1 & Traditional paper bound Issues & 4 & & \\
\hline E2 & Free daily emailed newsletters & 4 & & \\
\hline $\mathrm{F} 4$ & Reader customizable sections for special events or personal projects & 3 & & \\
\hline $\mathrm{E} 4$ & Issues sold independently at any newsstand or bookstore at around $\$ 3$ & 3 & & \\
\hline A6 & Tons of Useful Stuff & 3 & & \\
\hline $\mathrm{F} 2$ & Survey and poll taking opportunities with prizes & 2 & & \\
\hline E3 & Bundles of different magazines according to your preference of taste & 2 & & \\
\hline F6 & Job opportunities for the future reporters, photographers, and magazine editors & 2 & & \\
\hline E1 & Regularly mailed printed-Issues to your door & 0 & & \\
\hline B2 & Special issues featuring articles on famous television and music stars & 0 & & \\
\hline F3 & Advice column for the everyday reader & 0 & & \\
\hline E6 & PDF formatted issues emailed to the subscriber & -1 & & \\
\hline B1 & Seasonal offers style guides inspired by current trends in entertainment & -2 & & \\
\hline F5 & Internship opportunities for entrepreneur writers, photographers, graphic designers and future magazine editors & -3 & & \\
\hline D3 & Online viewable and mobile application so the reader can access the magazine at any time & -3 & & \\
\hline A4 & The Weekly Newsmagazine & -4 & & \\
\hline A5 & Write the word, submit the word, love the word. & -5 & & \\
\hline $\mathrm{C} 5$ & Free Posters in every issue featuring the hottest celebrities & -5 & & \\
\hline E5 & One time paid mobile apps with downloadable issues and articles on a weekly or monthly basis & -5 & & \\
\hline $\mathrm{C} 4$ & Sneak Previews of the upcoming year in music and entertainment & -6 & & \\
\hline A3 & Executives read it .. Uneducated ones look at the pictures & -6 & & \\
\hline D5 & Social network pages with up to the hour updates that can be discussed with friends & -7 & & \\
\hline A2 & Rockers read it. Pop Stars read it. & -9 & & \\
\hline
\end{tabular}


Howard Moskowitz (2022) The Mind of the Reader: Mind Genomics Cartographies of E-Readers versus ‘New' Magazines

Table 2B: Coefficients for the magazine, for total and two mind-sets, based on using all eight factors for clustering, factors derived from the 36 elements.

\begin{tabular}{|c|c|c|c|c|}
\hline & $\begin{array}{l}\text { Magazine Subscription, Total and Two Mindsets } \\
\text { Clustering based on eight derived factors from the elements }\end{array}$ & $\stackrel{\overrightarrow{0}}{\ddot{E}}$ & 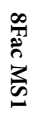 & 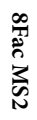 \\
\hline & Base size & 30 & 15 & 15 \\
\hline & Additive constant & 18 & 42 & -7 \\
\hline & Magazine-FAC Mind-Set1 - Job Opportunities & & & \\
\hline \multirow[t]{2}{*}{ F6 } & Job opportunities for the future reporters, photographers, and magazine editors & 2 & 20 & \\
\hline & Magazine-FAC Mind-Set2 - Information \& Experience & & & \\
\hline B5 & Exercise guides to get in shape for your special someone & 16 & & 33 \\
\hline B6 & In depth discussion of modern-day studies, research, and discoveries & 11 & & 30 \\
\hline B4 & Hidden city; best summer concerts, events, and specials & 14 & & 29 \\
\hline D2 & Magazine printed on $100 \%$ Recycled paper & 8 & & 29 \\
\hline B3 & Expanded CD review sections of the months new releases & 2 & & 23 \\
\hline E3 & Bundles of different magazines according to your preference of taste & 2 & & 22 \\
\hline C6 & Contests promoting traveling opportunities to exotic locations & 14 & & 21 \\
\hline E2 & Free daily emailed newsletters & 4 & & 20 \\
\hline B1 & Seasonal offers style guides inspired by current trends in entertainment & -2 & & 20 \\
\hline $\mathrm{C} 3$ & Sale Coupons to this season's hottest events and concerts & 6 & & 19 \\
\hline \multirow[t]{2}{*}{ D6 } & Daily Podcasts and Video Blogs via Internet and Email & 5 & & 17 \\
\hline & Magazine - FAC No strong appeal to either mind-set & & & \\
\hline $\mathrm{C} 1$ & Free soundtracks or movies per issue with subscription & 12 & & \\
\hline F1 & Section for reader's comments and questions & 7 & & \\
\hline D4 & Emailed newsletters sent to the reader & 6 & & \\
\hline D1 & Traditional paper bound Issues & 4 & & \\
\hline $\mathrm{F} 4$ & Reader customizable sections for special events or personal projects & 3 & & \\
\hline E4 & Issues sold independently at any newsstand or bookstore at around $\$ 3$ & 3 & & \\
\hline A6 & Tons of Useful Stuff & 3 & & \\
\hline $\mathrm{F} 2$ & Survey and poll taking opportunities with prizes & 2 & & \\
\hline E1 & Regularly mailed printed-Issues to your door & 0 & & \\
\hline $\mathrm{C} 2$ & Collectible artist of the year covers & 0 & & \\
\hline B2 & Special issues featuring articles on famous television and music stars & 0 & & \\
\hline F3 & Advice column for the everyday reader & 0 & & \\
\hline E6 & PDF formatted issues emailed to the subscriber & -1 & & \\
\hline A1 & What makes a man a gentleman ... Teaches you to "Look Sharp. Live Smart." & -2 & & \\
\hline F5 & Internship opportunities for entrepreneur writers, photographers, graphic designers and future magazine editors & -3 & & \\
\hline D3 & Online viewable and mobile application so the reader can access the magazine at any time & -3 & & \\
\hline A4 & The Weekly Newsmagazine & -4 & & \\
\hline A5 & Write the word, submit the word, love the word. & -5 & & \\
\hline C5 & Free Posters in every issue featuring the hottest celebrities & -5 & & \\
\hline E5 & One time paid mobile apps with downloadable issues and articles on a weekly or monthly basis & -5 & & \\
\hline C4 & Sneak Previews of the upcoming year in music and entertainment & -6 & & \\
\hline A3 & Executives read it.. Uneducated ones look at the pictures & -6 & & \\
\hline D5 & Social network pages with up to the hour updates that can be discussed with friends & -7 & & \\
\hline A2 & Rockers read it. Pop Stars read it. & -9 & & \\
\hline
\end{tabular}


grand abstraction that a marketer or 'creative' in an agency would propose as a coherent, summarizing theme. The responents want specifics.

\section{Step 8: Interpreting the Results - E-Book Readers}

Table $3 \mathrm{~A}$ shows the results for the E-book reader based upon the clustering into three groups. Unlike the findings for the magazine, the three mind-sets for the E-Book Reader made sense. Once again we see low additive constants. When we divide the respondents into mindsets based either upon the original 36 elements or upon the 15 factors emerging, we see two very low additive constants, and low additive constant around 27.

Like the results for magazines in Tables $2 \mathrm{~A}$ and $2 \mathrm{~B}$, we find that some coefficients are quite high, some of the highest ever recorded for a Mind Genomics study. The hypothesis proferred in the previous section may still hold, viz., that having young, colleage-age students, create the elements is the secret to strong performing elements. It may be that the students think in a more concrete, feature-oriented way, a way which generates a great deal more interest than professional creatives who may think of 'grand solutions', rather than of specific features. It may also be that the topic of e-book readers is by its nature simply far more interesting, and au courant

\section{Discussion and Conclusion}

\section{Why High Coefficients?}

The most surprising outcome from these two studies is the emergence of elements with exceptionally high coefficients. The studies were run in 2012, a decade ago, but that does not provide an explanation for the strong positive coefficients. Hypotheses about in the absence of fact. We have only two examples. What are common about them is that the elements are provided by young people (ages 18-21) rather than by professionals, viz., the so-called highly paid 'creatives' in the marketing companies and advertising agencies. and the topics talk to presentations of information, capabilities given to the reader or the user That is, the elements are fundamentally 'interesting' to the reader, not just simply recitations of what is. There is a sense of 'excitement', perhaps because we are talking about items with clearly interesting, people-oriented features. There are no elements dealing with 'good practices', elements that might be necessary in an offering but elements which really do not convince.

The notion that the topic is interesting certainly has merit in the world of Mind Genomics. Most Mind Genomics studies deal with social or medical issues, issues that are not 'interesting,' nor issues that people would pay for. Social problem, medical problems are issues about which one gathers information. The elements in this study are used to excite a buyer to buy the product. There is no sense of elements put in because they are legally necessary, or for completeness as one of recommended best practices.

\section{Polarized versus Non-polarized Mind-sets}

As noted above, the unusually high coefficients emerging from the total panel for some elements, and the exceptionally high coefficients emerging several times from the separate mind-sets, suggest that we are dealing with a new type of preference pattern, not frequently seen in Mind Genomics, but one easy to recognize. We are dealing with what one might call the 'pizza phenomenon'. Most people love pizza. It is the toppings which differentiate people. For most people it's a matter of order of preference, which varies from person to person. The result is that the total panel generates strong liking of the pizza, with the differentiator being the rank order of preference of the topping. There are people who actively dislike certain toppings, but for the most part the mind-sets that would emerge from a study of pizza and those representing different rank orders of items already liked.

In contrast to the above, the pizza phenomenon, where the mindsets are simply patterns of liking of the same elements, there are those situations where the person likes one element but hates another This pattern is very different from the pizza pattern. The pattern is more similar to the pattern of likes and dislikes of flavors. Flavors themselves strongly polarize people. Some people love a certain flavor, whereas others hate the flavor. One hears those words again and again.

Let's move this analogizing to the topics of e-book readers and magazine subscriptions. For the most part the coefficients are positive. There are relatively few elements which are strongly negative. There are no moderately negative elements for the e-book reader. Here are the most negative elements for the magazine

C4 Sneak Previews of the upcoming year in music and entertainment -6

A3
pictures

A2 Rockers read it. Pop Stars read it. -9

The patterns emerging for both the magazine (less so) and the e-book reader (more so) is that the creation of a product, especially one with electronic features (the e-book reader) is most likely to generate higher coefficients, than, for example a study on shopping for, using, or servicing the product.

\section{Developing a Culture of Iteration}

There is a culture in business which promotes experimentation, but does not prescribe what the experiment should be. The data presented here from students, rather than from experts, show a much greater 'success' in early stage experimentation. We see a great number of strong performing elements, yet many elements are still moderate performers. The results give hope that the number of strong positives can increase. With repeated efforts there should be more strong performing elements.

In business the process would be different. In most businesses the unspoken norm to 'manage for appearances.' That is, in business, people all too often manage each other, rather than managing for the best results. Bringing that observation to the world of Mind Genomics, the typical business approach would be to spend a long time preparing for the study, making sure that the elements are 'just right', and conducting the Mind Genomics experiment with several hundred 
Table 3A: Coefficients for the magazine, for total and three mind-sets, based on using all 36 elements for clustering.

\begin{tabular}{|c|c|c|c|c|c|}
\hline & $\begin{array}{l}\text { E-Book Readers:, Total and Three Mindsets } \\
\text { Clustering based on all } 36 \text { elements }\end{array}$ & $\stackrel{\overrightarrow{0}}{\ddot{D}}$ & 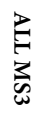 & $\underset{2}{3}$ & 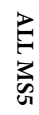 \\
\hline & Base size & 52 & 17 & 18 & 17 \\
\hline & Additive constant & 10 & -1 & 5 & 27 \\
\hline & $\begin{array}{l}\text { E-Book Reader ALL Mind-Set 3: } \\
\text { Focus on ease of use, versatility, low cost }\end{array}$ & & & & \\
\hline $\mathrm{F} 2$ & Hands on easy to use... no more carrying books & 5 & 35 & & \\
\hline $\mathrm{C} 3$ & Rent or buy popular movie and TV shows & 15 & 35 & & \\
\hline $\mathrm{C} 5$ & Audio reader is now available to you through E-Book & 5 & 31 & & \\
\hline E4 & Free trial for three weeks & 15 & 30 & & \\
\hline $\mathrm{C} 1$ & You can now view over 300 million books on one tablet & 12 & 29 & & 15 \\
\hline $\mathrm{C} 2$ & Read your favorite magazines, catalogs, and newspapers & 3 & 22 & & \\
\hline C6 & More apps for your business and studying & 5 & 18 & & \\
\hline E5 & Wi-Fi enable to download books real time & 3 & 18 & & \\
\hline A5 & Solar panel technology allows you to recharge through clean recyclable energy & 14 & 18 & 29 & \\
\hline \multirow[t]{2}{*}{ E1 } & Promotes reading with the ability to put several book titles within your tablet & 4 & 17 & & \\
\hline & E-Book Reader ALL Mind-Set 4: Ease of use, appeal to ecological benefits & & & & \\
\hline A1 & Ability to write notes within the tablet therefore lowering the need/production of highlighters/pens & 11 & & 44 & \\
\hline D3 & Competitively priced to meet your needs & 11 & & 30 & \\
\hline A5 & Solar panel technology allows you to recharge through clean recyclable energy & 14 & 18 & 29 & \\
\hline $\mathrm{D} 2$ & Highest quality of E-Book available today & 5 & & 29 & \\
\hline F3 & Security systems allow you and only you to access your software & 10 & & 28 & \\
\hline D5 & Use your friendly menu system & 8 & & 24 & \\
\hline A3 & Start breathing in a fresh air & 5 & & 24 & \\
\hline A2 & Fewer trees cut for paper equals more fresh breathable air & 10 & & 21 & \\
\hline D1 & Access to the latest technology & 8 & 16 & 20 & \\
\hline A6 & Fewer trees cut down means animals won't lose their habitat & 10 & & 19 & \\
\hline A4 & Save trees....save the woods, forest & 4 & & 19 & \\
\hline D6 & Tablet made of durable material & 6 & & 19 & \\
\hline D4 & Long lengthy battery life & 0 & & 16 & \\
\hline \multirow[t]{2}{*}{ F6 } & Color screen for real life reading experience & 2 & & 15 & \\
\hline & \begin{tabular}{|l|} 
E-Book Reader ALL Mind-Set5: \\
Focus on books, and screen (reading focused) \\
\end{tabular} & & & & \\
\hline B5 & Instead of carrying heavy books... try carrying e-books & 9 & & & 39 \\
\hline B2 & Carry thousands of books on one device & 1 & & & 20 \\
\hline B1 & Touchable color screen that's precise & 2 & & & 19 \\
\hline B3 & Choose small or large LCD screen & 7 & & & 17 \\
\hline \multirow[t]{2}{*}{$\mathrm{C} 1$} & You can now view over 300 million books on one tablet & 12 & 29 & & 15 \\
\hline & E-Book Reader - No strong appeal to any mind-set & & & & \\
\hline E6 & Become more "tech savvy" with the process of downloading & 5 & & & \\
\hline E3 & Life and your future can change... read & 5 & & & \\
\hline $\mathrm{C} 4$ & Play your favorite games on E-Book & 4 & & & \\
\hline B6 & Choose your color... Black or Grey & 1 & & & \\
\hline $\mathrm{F} 4$ & Latest screen technology makes your book crystal clear to read & -1 & & & \\
\hline B4 & Made of durable material "shock resistant" & -2 & & & \\
\hline E2 & Expend your horizon with more knowledge & -2 & & & \\
\hline F1 & Software download is now easy and fast & -4 & & & \\
\hline F5 & Access world of books with a single touch & -5 & & & \\
\hline
\end{tabular}


Howard Moskowitz (2022) The Mind of the Reader: Mind Genomics Cartographies of E-Readers versus ‘New' Magazines

Table 3B: Coefficients for the magazine, for total and three mind-sets, based on using all 15 factors for clustering, factors derived from the 36 elements.

\begin{tabular}{|c|c|c|c|c|c|}
\hline & $\begin{array}{l}\text { E-Book Reader, Total and Three Mindsets } \\
\text { Clustering based on } 15 \text { factors derived from the elements }\end{array}$ & $\stackrel{\overrightarrow{0}}{\ddot{E}}$ & 㞼藏 & 学 & 光芴 \\
\hline & Base size & 52 & 21 & 15 & 16 \\
\hline & Additive constant & 10 & 27 & -7 & 5 \\
\hline & E-Book Reader - FAC Mind-Set3 - Free trial & & & & \\
\hline \multirow[t]{2}{*}{$\mathrm{E} 4$} & Free trial for three weeks & 15 & 19 & & 25 \\
\hline & E-Book Reader - FAC Mind-Set 4 - Ecology, capacity, convenience. & & & & \\
\hline A5 & Solar panel technology allows you to recharge through clean recyclable energy & 14 & & 39 & 25 \\
\hline A2 & Fewer trees cut for paper equals more fresh breathable air & 10 & & 36 & 19 \\
\hline A1 & Ability to write notes within the tablet therefore lowering the need/production of highlighters/pens & 11 & & 36 & \\
\hline A6 & Fewer trees cut down means animals won't lose their habitat & 10 & & 32 & \\
\hline D5 & Use your friendly menu system & 8 & & 31 & \\
\hline $\mathrm{C} 3$ & Rent or buy popular movie and TV shows & 15 & & 31 & 16 \\
\hline B5 & Instead of carrying heavy books... try carrying e-books & 9 & & 25 & \\
\hline B3 & Choose small or large LCD screen & 7 & & 24 & \\
\hline D6 & Tablet made of durable material & 6 & & 24 & \\
\hline $\mathrm{C} 1$ & You can now view over 300 million books on one tablet & 12 & & 23 & 23 \\
\hline A3 & Start breathing in a fresh air & 5 & & 23 & \\
\hline $\mathrm{C} 4$ & Play your favorite games on E-Book & 4 & & 17 & \\
\hline \multirow[t]{2}{*}{$\mathrm{B} 2$} & Carry thousands of books on one device & 1 & & 15 & \\
\hline & E-Book Reader - FAC Mind-Set 5 - Miscellaneous & & & & \\
\hline E3 & Life and your future can change... read & 5 & & & 33 \\
\hline F3 & Security systems allow you and only you to access your software & 10 & & & 32 \\
\hline E4 & Free trial for three weeks & 15 & 19 & & 25 \\
\hline D3 & Competitively priced to meet your needs & 11 & & & 25 \\
\hline A5 & Solar panel technology allows you to recharge through clean recyclable energy & 14 & & 39 & 25 \\
\hline $\mathrm{C} 1$ & You can now view over 300 million books on one tablet & 12 & & 23 & 23 \\
\hline F2 & Hands on easy to use... no more carrying books & 5 & & & 21 \\
\hline A2 & Fewer trees cut for paper equals more fresh breathable air & 10 & & 36 & 19 \\
\hline D2 & Highest quality of E-Book available today & 5 & & & 19 \\
\hline E2 & Expend your horizon with more knowledge & -2 & & & 17 \\
\hline C5 & Audio reader is now available to you through E-Book & 5 & & & 16 \\
\hline $\mathrm{C} 3$ & Rent or buy popular movie and TV shows & 15 & & 31 & 16 \\
\hline \multirow[t]{2}{*}{ E5 } & Wi-Fi enable to download books real time & 3 & & & 16 \\
\hline & E-Book Reader - No strong appeal to any mind-set & & & & \\
\hline D1 & Access to the latest technology & 8 & & & \\
\hline E6 & Become more "tech savvy" with the process of downloading & 5 & & & \\
\hline C6 & More apps for your business and studying & 5 & & & \\
\hline E1 & Promotes reading with the ability to put several book titles within your tablet & 4 & & & \\
\hline A4 & Save trees....save the woods, forest & 4 & & & \\
\hline $\mathrm{C} 2$ & Read your favorite magazines, catalogs, and newspapers & 3 & & & \\
\hline B1 & Touchable color screen that's precise & 2 & & & \\
\hline F6 & Color screen for real life reading experience & 2 & & & \\
\hline B6 & Choose your color... Black or Grey & 1 & & & \\
\hline D4 & Long lengthy battery life & 0 & & & \\
\hline $\mathrm{F} 4$ & Latest screen technology makes your book crystal clear to read & -1 & & & \\
\hline B4 & Made of durable material "shock resistant" & -2 & & & \\
\hline $\mathrm{F} 1$ & Software download is now easy and fast & -4 & & & \\
\hline F5 & Access world of books with a single touch & -5 & & & \\
\hline
\end{tabular}


people, to ensure that 'the results are solid.' This approach of 'letting the perfect be the enemy of the good' ends up generating one wellprepared Mind Genomics study. The effort is expended in the wrong way. The effort should be on iterating, with small Mind Genomics experiment, each with 50 respondents, each done in the space of no more than 24 hours. The study here, run by students, relative amateurs in the world of business, shows the power of 'just doing it.

\section{Appendix}

The effort to create this system generated a patented approach (REF), available now world-wide, on an automated basis, for a reduced size (4 questions, 4 answers or elements). The system is essentially free, except for minor processing charges on a per respondent basis to defray the maintenance. The website is www.BimiLeap.com

\section{References}

1. Witepski L (2006) When is a magazine not a magazine? Journal of Marketing 2: 34-37.

2. Behler A, Lush B (2010) Are you ready for e-readers? The Reference Librarian 52: 75-87.

3. Griffey J (2012) E-readers now, e-readers forever!. Library technology reports 43: 1420 .

4. Massis BE (2010) E-book readers and college students. New Library World 111: 347350

5. Thayer A, Lee CP, Hwang LH, Sales H, Sen P, et al. (2011) The imposition and superimposition of digital reading technology: the academic potential of e-readers. In Proceedings of the SIGCHI Conference on Human Factors in Computing Systems 29: 17-26.

6. Williams MD, Slade EL, Dwivedi YK (2014) Consumers' intentions to use e-readers. Journal of Computer Information Systems 54: 66-76.

7. Milutinovic V, Salom J (2016) Introduction to basic concepts of Mind Genomics. In: Mind Genomics. Springer, Cham 1-29.

8. Moskowitz H, Rappaport S, Moskowitz D, Porretta S, Velema B, et al. (2017) Product design for bread through mind genomics and cognitive economics. In: Developing New Functional Food and Nutraceutical Products. Academic Press 249-278.

9. Moskowitz HR, Gofman A (2007) Selling Blue Elephants: How to Make Great Products that People Want Before They Know They Even Want Them. Pearson Education.

10. Gofman A, Moskowitz H (2010) Isomorphic permuted experimental designs and their application in conjoint analysis. Journal of Sensory Studies 25: 127-145.

11. Kanungo T, Mount DM, Netanyahu NS, Piatko CD, Silverman R, et al. (2002) An efficient k-means clustering algorithm: Analysis and implementation. IEEE Transactions on Pattern Analysis and Machine Intelligence 24: 881-892.

12. Gere A, Moskowitz H (2021) Assigning people to empirically uncovered mind-sets: A new horizon to understand the minds and behaviors of people. In Consumerbased New Product Development for the Food Industry. Royal Society of Chemistry 132-149.

13. Widaman KF (1993) Common factor analysis versus principal component analysis: Differential bias in representing model parameters?. Multivariate Behavioral Research 28: 263-311.

14. Aldenderfer MS, Blashfield RK (1984) Cluster Analysis, Sage Publications, Beverly Hills, CA.

15. Fiedler J, McDonald JJ (1993) Market figmentation: Clustering on factor scores versus individual variables. Paper Presented to the AMA Advanced Research Techniques Forum.

16. Huhmann BA, Brotherton TP (1997) A content analysis of guilt appeals in popular magazine advertisements. Journal of Advertising 26: 35-45.

\section{Citation:}

Moskowitz H, Savicevic K, Braun M, Rodriguez LE (2022) The Mind of the Reader: Mind Genomics Cartographies of E-Readers versus 'New' Magazines. Psychol J Res Open Volume 4(1): 1-13. 